\title{
INTRODUCING THE ANALYTIC HIERARCHY PROCESS: A MATHEMATICAL HOMEWORK
}

\author{
Fernando Alves Leite \\ Fernando Ribeiro Guglielmetti \\ Marcus Eduardo Gonçalves \\ Valério A. P. Salomon \\ Universidade Estadual Paulista (UNESP) \\ Guaratinguetá /SP - Brazil \\ salomon@feg.unesp.br
}

Keywords: Education, Industrial Engineering, Mathematics, Transportation

Summary: This work shows the approach of Analytic Hierarchy Process in a mathematical homework. This homework is an activity that must be developed by Industrial Engineering undergraduation students with specific objectives as to motivate the students and to introduce the use of mathematical tolls. Other great point showed in this work is the contribution of that activity as a part of a greater research involving others professors and students which has needed an alternative, interesting and systematized decision support tool named Analytic Hierarchy Process.

\section{Introduction}

It was developed an Industrial Engineering research (Salomon, 2000) involving two professors, three Mechanical Engineering Trainees and three Industrial Engineering undergraduation students. This research aim the decision support for an Industrial Engineering process: the procurement process. The roles for this research participants was the Trainees has developed graduation work approaching the procurement process; the Industrial Engineering students developed a mathematical homework; the professors had advised these works.

The mathematical homework has got three specific objectives; to motivate the Industrial Engineering study, to show mathematical tools applying, to capacitate the student for the mathematical modeling of problems (Coordination of Industrial Engineering undergraduation course, 1995). In order to achieve these objectives, the coordination of Industrial engineering undergraduation course invites Professors to propose themes for the mathematical homework.

The practical example proposed in the mathematical homework will be presented followed by some considerations concluding the benefits of their making.

\section{Using the Analytic Hierarchy Process}

It was proposed, as a real problem regarding to industrial Engineering "to choose the best transportation way for electronic products in Brazil". There was identified five most important criteria:

1. Time of delivery

2. Level of defects

3. Misleading numbers

4. Practicability of this transportation in Brazil

5. Reclamation (refers a bad treatment by drivers or workers)

We have the four alternatives to selection presented in figure 1. 


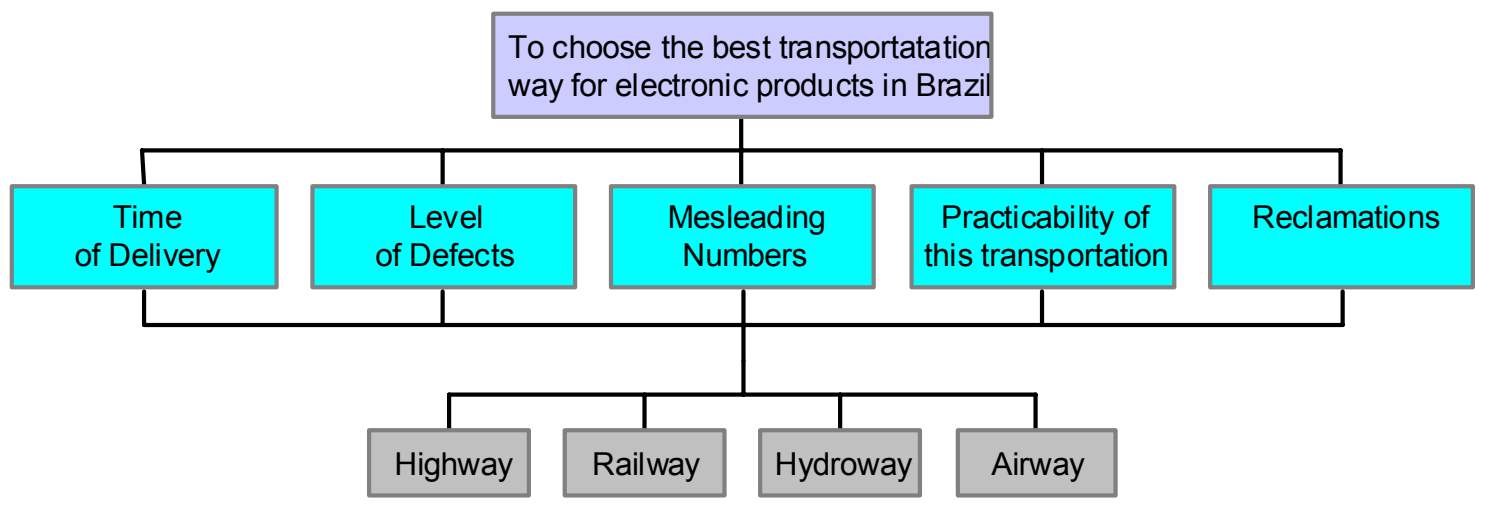

Figure 1 - Decision hierarchy structure

Table 1 shows the criteria pairwise judgments and their priorities obtained by na eigenvector estimation.. With these data we came to $\lambda_{\mathrm{MAX}}$ and consistency ratio (CR) values equal to 5.442 e 0.099 , respectively. These indicate judgments not totally consistent. But, they can be accept, as proposed by Saaty (1980). The table shows Practicability as the most important criterion.

\begin{tabular}{|l|c|c|c|c|c|c|}
\cline { 2 - 7 } \multicolumn{1}{c|}{} & Delivery & Defects & Misleading & Practicability & Reclamation & Eigenvector \\
\hline Delivery & 1 & $1 / 3$ & 3 & $1 / 9$ & 1 & 0.076 \\
\hline Defects & 3 & 1 & 3 & $1 / 9$ & $1 / 3$ & 0.094 \\
\hline Misleading & $1 / 3$ & $1 / 3$ & 1 & $1 / 9$ & 3 & 0.061 \\
\hline Practicability & 9 & 9 & 9 & 1 & 9 & 0.680 \\
\hline Reclamation & 1 & 3 & $1 / 3$ & $1 / 9$ & 1 & 0.076 \\
\hline
\end{tabular}

Table 1 - Criteria importance

The next step was the alternatives pairwise comparisons for each criterion, in order to obtain the satisfaction ranking which each alternative proportionates to each criterion. This results are showed in tables 2 to 6 .

\begin{tabular}{|l|c|c|c|c|c|}
\cline { 2 - 6 } \multicolumn{1}{c|}{} & Airway & Railway & Hydroway & Highway & Eigenvector \\
\hline Airway & 1 & 7 & 9 & 5 & 0.657 \\
\hline Railway & $1 / 7$ & 1 & 2 & $1 / 3$ & 0.087 \\
\hline Hydroway & $1 / 9$ & $1 / 2$ & 1 & $1 / 5$ & 0.051 \\
\hline Highway & $1 / 5$ & 3 & 5 & 1 & 0.205 \\
\hline
\end{tabular}

Table 2 - Satisfaction to Delivery

The judgments showed in table 2 can be accept because they engender $\lambda_{\text {MAX }}$ and CR values, respectively, equal to 4.16 and 0.058 .

\begin{tabular}{|c|c|c|c|c|}
\hline Airway & Railway & Hydroway & Highway & Eigenvector \\
\hline
\end{tabular}




\begin{tabular}{|l|c|c|c|c|c|}
\hline Airway & 1 & 7 & 9 & 4 & 0.634 \\
\hline Railway & $1 / 7$ & 1 & 3 & $1 / 3$ & 0.098 \\
\hline Hydroway & $1 / 9$ & $1 / 3$ & 1 & $1 / 5$ & 0.047 \\
\hline Highway & $1 / 4$ & 3 & 5 & 1 & 0.221 \\
\hline
\end{tabular}

Table 3 - Satisfaction to Defects

The judgments showed in table 3 can be accept because they engender $\lambda_{\text {MAX }}$ and CR values, respectively, equal to 4.13 and 0.049 .

\begin{tabular}{|l|c|c|c|c|c|}
\cline { 2 - 6 } \multicolumn{1}{c|}{} & Airway & Railway & Hydroway & Highway & Eigenvector \\
\hline Airway & 1 & 3 & $1 / 2$ & 8 & 0.345 \\
\hline Railway & $1 / 3$ & 1 & $1 / 2$ & 6 & 0.185 \\
\hline Hydroway & 2 & 2 & 1 & 7 & 0.426 \\
\hline Highway & $1 / 8$ & $1 / 6$ & $1 / 7$ & 1 & 0.043 \\
\hline
\end{tabular}

Table 4 - Satisfaction to Misleading

The judgments showed in table 4 can be accept because they engender $\lambda_{\text {MAX }}$ and CR values, respectively, equal to 4.20 and 0.076 .

\begin{tabular}{|l|c|c|c|c|c|}
\cline { 2 - 6 } \multicolumn{1}{c|}{} & Airway & Railway & Hydroway & Highway & Eigenvector \\
\hline Airway & 1 & 4 & 4 & $1 / 4$ & 0.223 \\
\hline Railway & $1 / 4$ & 1 & 3 & $1 / 8$ & 0.087 \\
\hline Hydroway & $1 / 4$ & $1 / 3$ & 1 & $1 / 8$ & 0.058 \\
\hline Highway & 4 & 8 & 8 & 1 & 0.632 \\
\hline
\end{tabular}

Table 5 - Satisfaction to Practicability

The judgments showed in table 5 can be accept because they engender $\lambda_{\text {MAX }}$ and CR values, respectively equal to 4.32 e 0.12 .

\begin{tabular}{|l|c|c|c|c|c|}
\cline { 2 - 6 } \multicolumn{1}{c|}{} & Airway & Railway & Hydroway & Highway & Eigenvector \\
\hline Airway & 1 & 2 & 2 & 4 & 0.433 \\
\hline Railway & $1 / 2$ & 1 & 1 & 3 & 0.239 \\
\hline Hydroway & $1 / 2$ & 1 & 1 & 3 & 0.239 \\
\hline Highway & $1 / 4$ & $1 / 3$ & $1 / 3$ & 1 & 0.088 \\
\hline
\end{tabular}

Table 6 - Satisfaction to Reclamation

The judgments showed in table 5 can be accept because they engender $\lambda_{\text {MAX }}$ and CR values, respectively equal to 4.02 and 0.008 . 
The table 7 summarizes the priorities for the alternatives from all criteria.

\begin{tabular}{|l|c|c|c|c|c|}
\cline { 3 - 6 } \multicolumn{2}{c|}{} & \multicolumn{4}{c|}{ Alternatives } \\
\hline Criteria & Airway & Railway & Hydroway & Highway \\
\hline Delivery & 0.076 & 0.657 & 0.087 & 0.051 & 0.205 \\
\hline Defects & 0.094 & 0.634 & 0.098 & 0.047 & 0.221 \\
\hline Misleading & 0.061 & 0.345 & 0.185 & 0.426 & 0.043 \\
\hline Practicability & 0.680 & 0.223 & 0.087 & 0.058 & 0.632 \\
\hline Reclamation & 0.076 & 0.433 & 0.239 & 0.239 & 0.088 \\
\hline
\end{tabular}

Table 7 - Decision matrix

Weighting the elements of the Decision matrix with the criteria priorities showed in table 1 we have the decision vector presented by table 8 . Based on this results, we may conclude that Highway was the best transportation way for electronic products in Brazil, with priority around $47 \%$.

\begin{tabular}{|l|c|}
\cline { 2 - 2 } \multicolumn{1}{c|}{} & Global Priorities \\
\hline Airway & 0.315 \\
\hline Railway & 0.104 \\
\hline Hydroway & 0.092 \\
\hline Highway & 0.474 \\
\hline
\end{tabular}

Table 8 - Decision Vector

\section{Conclusions}

The judgments provide a high global consistency ratio, but still acceptable (0.098). However, the alternatives pairwise comparisons for practicability should be reviewed: they provide a CR equal to 0.12 . This high unacceptable value can clearly justified to the low level of knowledge of the students (that performed the comparisons) about this topic. This fail can be reduced with this topic research (economics and technical features of the transportation way), but, this not inside the original scope of objectives of the homework. Judgments review highlights as a new topic to be studied by students in later works.

It is very important to relate that the works performed by the Trainees has been considered successful. The Analytic Hierarchy Process application were a key factor for all of them. It was possible to better select suppliers (Caçador, 1999), equipment (Ivo, 1999) and so on. The applications by the Trainees was facilitated by the mathematical homework: in the middle of the year the students who developed that homework has presented a theoretical introduction about this method to the other participants of the research. 


\section{References $^{1}$}

Caçador, F. F. (1999), Usual Procurement Process Analysis, Mechanical Engineering undergraduation work, Guaratinguetá (Brazil): Universidade Estadual Paulista

Coordination of the Industrial Engineering Undergraduation Course (1995), Pedagogical Design, Guaratinguetá (Brazil): Universidade Estadual Paulista

Ivo, H. R. (1999), Support to Managerial decision Making by Engineers, Mechanical Engineering undergraduation work, Guaratinguetá (Brazil): Universidade Estadual Paulista

Saaty, T. L. (1980), The Analytic Hierarchy Process: Planning, Priority, Setting and Resource Allocation, New York: McGraw-Hill, Inc.

Salomon, V. A. P. (2000), Decision Support For The New Procurement Policies Adoption, Guaratinguetá (Brazil): Universidade Estadual Paulista

\footnotetext{
${ }^{1}$ For better understanding we have translated the original tittles of Brazilian references to English
} 
